\title{
Osmotic Drying Rate Estimation for Dehydration of Beetroot Slices using Artificial Neural Network
}

\author{
Shekhar Pandharipande \\ Associate Professor, Department of Chemical \\ Engineering, Laxminarayan Institute of Technology, \\ Rashtrasant Tukadoji Maharaj Nagpur University, \\ Bharat Nagar, Amravati Road, Nagpur, India.
}

\author{
Bhushan Bele \\ B. Tech. Chemical Engineering. \\ Laxminarayan Institute of Technology, \\ Rashtrasant Tukadoji Maharaj Nagpur University, \\ Bharat Nagar, Amravati Road, Nagpur, India.
}

\begin{abstract}
Osmotic dehydration can be viewed as an alternative method for drying of food materials with advantages of retention of gloss, texture \& colour of dried products. Artificial neural network is emerging as a modeling tool for complex operations involving non linear multivariable relationships. The present work is aimed at estimation of the osmotic drying rates \& weight reduction of beetroot slices as a function of concentration of sodium chloride, time \& temperature using artificial neural network. Based on the observations, results \& discussion, it can be said that, beetroot slices can be partially dewatered by osmotic dehydration in salt solution and percent weight loss is from 10 to $29 \%$ depending upon the operating parameters. It can be concluded that the present work has successfully demonstrated the potential of ANN in modeling of osmotic dehydration of beetroot slices with high accuracy.
\end{abstract}

Keywords: Osmotic dehydration, Artificial neural network modeling, Beetroot slices

\section{INTRODUCTION}

Drying is a method of food preservation that works by removing water from the food, which inhibits the growth of microorganisms. Osmotic dehydration has been investigated by researchers and scientist as an alternative method for drying of food materials.

Osmotic dehydration is gaining importance as an alternative process of dehydrating fruits and vegetables. It is an efficient water removal method due to its major advantage of retention of gloss, texture \& colour of dried products. In osmotic dehydration, the material is immersed in a osmotic solution which is usually a concentrated solution of sucrose or sodium chloride in water. The mechanism of water removal is based on the natural and non-destructive phenomenon of osmosis across cell membrane \& the diffusion of water from the material into the solution results due to the higher osmotic pressure of the osmotic solution. The process of dehydration is accompanied by the counter diffusion of solutes from the osmotic solution into the material. Osmotic dehydration is used as a pretreatment to improve nutritional, sensorial and functional properties of food. The use of the osmotic dehydration process in the food industry has several advantages; quality improvement, energy efficiency, packaging and distribution cost reduction, better product stability and retention of nutrients during storage.

Beetroot or beet is a flowering plant species in the family Chenopodiaceous \& can be peeled, steamed, cooked, pickled, shredded raw, in order to make it eatable. Betanin, obtained from the roots, is used industrially as red food colorants, e.g. to improve the color and flavor of tomato paste, sauces, desserts, jams and jellies, ice cream, sweets and breakfast cereals.

There are numerous studies on osmotic dehydration of vegetables. Various researchers have investigated the effect of varying conditions of temperature, concentration and time duration on water loss solid gain and weight reduction.

P. Manivannan and M. Rajasimman developed quadratic regression equations describing the effects of temperature (25$45^{\circ} \mathrm{C}$ ), time duration (30-150min), salt concentration $(5-25 \%$, $\mathrm{w} / \mathrm{w})$ and solution to sample ratio $(5: 1-25: 1)$ on the water loss and solids gain [1]. Abhijit Kar reported his work related to osmotic dehydration of banana slices and used Response Surface Methodology to optimize the osmotic dehydration with special reference to maximum moisture removal and minimum solids gain [2]. Graziella C. Antonio studied osmotic dehydration of papaya slices and found that temperature and sample geometry had more influence on water loss and weight loss, followed by sucrose and lactic acid concentration they had also observed that slices provided more water loss, weight loss and solid gain than cubic geometry [3]. Nikolaos E. Mavroudis investigated effects of agitation and structural differences on osmotic dehydration [4]. Md. Shafiq Alam used Response Surface Methodology to investigate the effect of sugar concentration (50-70 Brix), solution temperature (30$\left.60^{\circ} \mathrm{C}\right)$, solution to fruit ratio $(4: 1-8: 1)$ and immersion time (60-180 $\mathrm{min})$ on the water loss, solute gain, rehydration ratio, vitamin-C loss, colour change and sensory overall acceptability of Indian gooseberry (aonla) slices [5]. Gordana B. Koprivica studied osmotic dehydration process of carrot in sugar beet molasses solutions and investigated the effects of immersion time, working temperature and molasses concentration on mass transfer kinetics during osmotic dehydration [6]. Fernanda E. X. Murr studied the effects of temperature $\left(11.9\right.$ to $33.1^{\circ} \mathrm{C}$ ) and $\mathrm{NaCl}$ concentration (3 to 17 $\% \mathrm{w} / \mathrm{w}$ ) on solid gain and water loss ratio (SG/WL) during osmotic dehydration process of carrot [7].

Artificial Neural Network (ANN) is emerging as an interdisciplinary theme for modeling of complex processes involving non linear multivariable correlation ships. It is inspired by the way biological neural network processes information. It is composed of large number of highly interconnected processing elements called as nodes or neurons working together to solve a specific problem [8]. Multi Layer Perception (MLP) is the most common type of feed forward neural network employed for chemical engineering applications. It consists of more than two layers of a hierarchical structure of input and output layers \& at least one hidden layer of processing units in between them. The nodes or 
neurons between the two successive layers are connected to each other by means of constants called as weights. The outputs from the input layer act as input for hidden layer nodes, which in turn, feed their outputs to the nodes of the next layer. Logistic sigmoid or hyperbolic tangent functions may be used as an activation function to transform the signal. The power of neural network is in its training \& algorithm suggested by Rumelhart [9] is popular in this regard. This is based on a nonlinear version of the Widro-Hoff rule known as Generalized Delta Rule (GDR). Various applications of ANN are an approach to fault diagnosis in chemical processes [10]. fault diagnosis in complex chemical plants [11], incipient fault diagnosis of chemical process [12], leak detection in liquefied gas pipeline (AIChE 44 (12), (1998))[13], leak detection in liquefied gas pipeline (Chem. Engg. World 38(6) (2003))[14], Modeling of Osmotic Dehydration Kinetics of Banana Slices using Artificial Neural Network [15] etc.

\section{PRESENT WORK}

The objective of the present work is to study the effect of concentration of sodium chloride \& temperature of the osmotic solution on the osmotic dehydration of beetroot slices. The work is further extended in developing Artificial Neural network models for estimation of the drying rates \& weight reduction of slices as a function of concentration of sodium chloride, time \& temperature using "elite- $\mathrm{ANN}^{\circledR},[16]$.

Fresh beetroots purchased locally, were thoroughly washed with water to remove adhering soil and other debris. Then, they were cut into slices of $45-50 \mathrm{~mm}$ diameter and $2 \mathrm{~mm}$ thickness. The osmotic solution is prepared by dissolving weighed quantity of sodium chloride in proper amount of pure water.

\subsection{Experimental Procedure:}

Beetroot slices were weighed \& placed into a glass vessel containing sodium chloride solution of known concentration. The glass vessel was put into an oven maintained at constant temperature. The slices were removed after every fifteen minutes, gently blotted with adsorbent paper \& weighed. The observations were repeated till constant weight is obtained. The entire procedure is repeated for various concentration \& temperature conditions.

The observations were noted down as shown in sample table no. $1 \&$ the $\%$ weight reduction and osmotic drying rate was calculated for each observation using following expressions.

$\%$ Weight loss $=\left(\mathrm{W}_{0}-\mathrm{W}_{\mathrm{t}}\right) / \mathrm{W}_{0} * 100$;

Osmotic drying rate $=\left(\mathrm{W}_{1}-\mathrm{W}_{2}\right) / 15$

Where,

$\mathrm{W}_{0}=$ Initial weight at time $\mathrm{t}=0 ; \mathrm{W}_{\mathrm{t}}=$ Final weight at time $\mathrm{t}$;

$W_{1}=$ Weight at time $t_{1} ; W_{2}=$ Weight at time $t_{2}\left(\right.$ i.e. $\left.t_{1}+15\right)$.

Table 1. Sample Observation Table

\begin{tabular}{|l|c|c|c|c|}
\hline \multicolumn{3}{|l|}{ Room temperature:__ Solution temperature: } \\
\hline Sr. & Time & \multicolumn{3}{|c|}{ Weight of beetroot slices (g) } \\
\cline { 3 - 5 } No. & (min) & $\begin{array}{c}\text { Concentratio } \\
\text { n 10\% }\end{array}$ & $\begin{array}{c}\text { Concentratio } \\
\text { n } 15 \%\end{array}$ & $\begin{array}{c}\text { Concentratio } \\
\text { n } 20 \%\end{array}$ \\
\hline
\end{tabular}

\section{RESULT AND DISCUSSIONS}

\subsection{Effect of solution concentration on} weight loss

Figure no. 1 to 5 depict the graphs plotted between the parameters weight loss of beetroot slices with time for constant temperature condition of $25^{\circ} \mathrm{C}, 30^{\circ} \mathrm{C}, 35^{\circ} \mathrm{C}, 40^{\circ} \mathrm{C} \& 45^{\circ} \mathrm{C}$ having salt concentration of $10 \%, 15 \% \& 20 \%$ respectively. It can be seen from the nature of the graphs that there is a rise in the $\%$ weight reduction initially, reaches maximum after some time \& becomes constant thereafter for each case. The negative slope of the weight reduction as can be seen in some cases is indicative of the weight gain (solid gain) by beetroot slice.

\subsection{Effect of solution concentration on drying rate}

Figure no. 6 to 10 show the graphs plotted between the osmotic drying rates as a function of time. There is a remarkable similarity in the nature of these graphs. The drying rate increases in the first 15 minutes reaches maximum, then drops \& touches zero, indicating equilibrium was reached. It is also observed that if the operation is continued, then the rate becomes negative indicating the reversal of direction of transfer of sodium chloride solution to the material. The range of the osmotic drying rate obtained is between 0.04 to 0.11 $\mathrm{g} / \mathrm{min}$ depending upon the conditions of temperature, concentration and time.

Based on the visual observation of dried sample it can be seen that

- No or very little change in the colour of the samples.

- No shrinkage or swirly nature of dried product was observed.

- Dehydrated slices were having low hardness as well as high softness than the fresh ones.

Fungal attack was observed on dehydrated slices which was successfully restricted or minimized by adding a small amount of sodium benzoate in the osmotic solution.

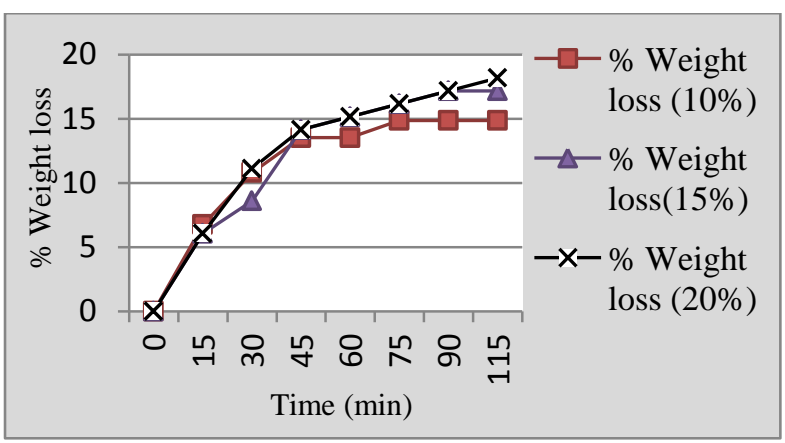

Figure 1. Weight loss: constant solution temperature of $25^{\circ} \mathrm{C}$ and varying concentration 


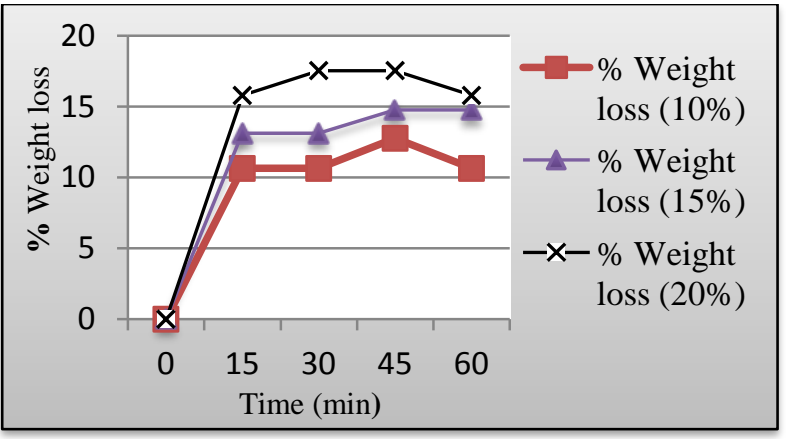

Figure 2. Weight loss: constant solution temperature of $30^{\circ} \mathrm{C}$ and varying concentration

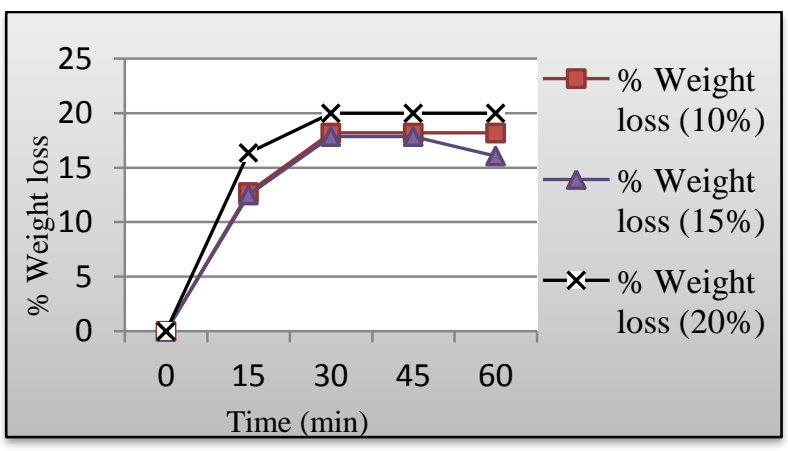

Figure 3. Weight loss: constant solution temperature of $35^{\circ} \mathrm{C}$ and varying concentration

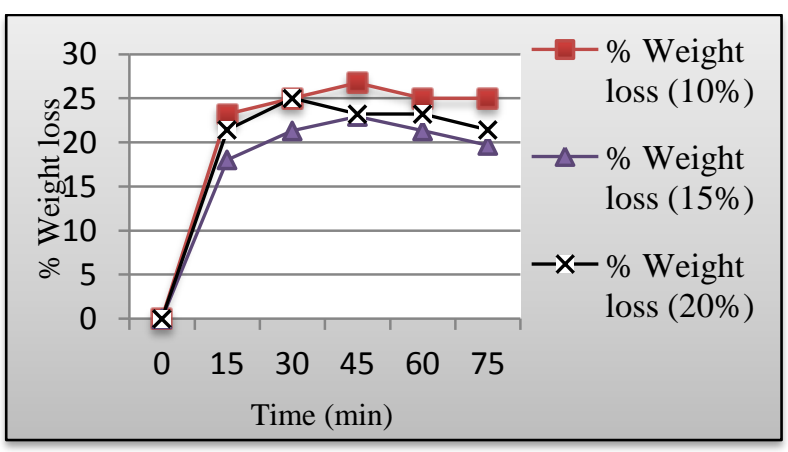

Figure 4. Weight loss: constant solution temperature of $40^{\circ} \mathrm{C}$ and varying concentration

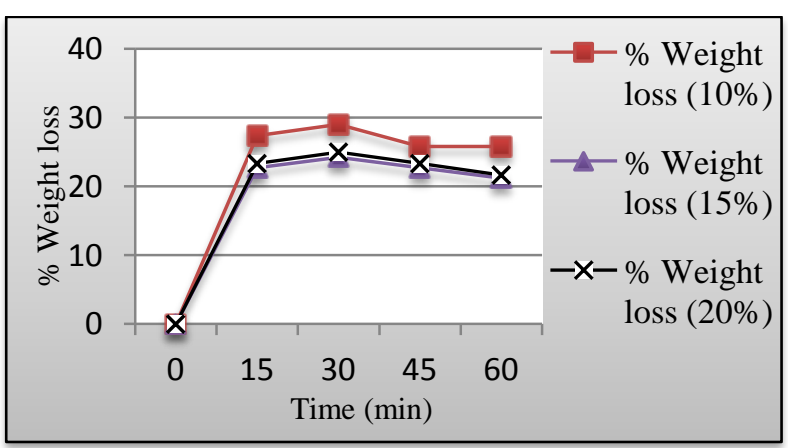

Figure 5. Weight loss: constant solution temperature of $45^{\circ} \mathrm{C}$ and varying concentration

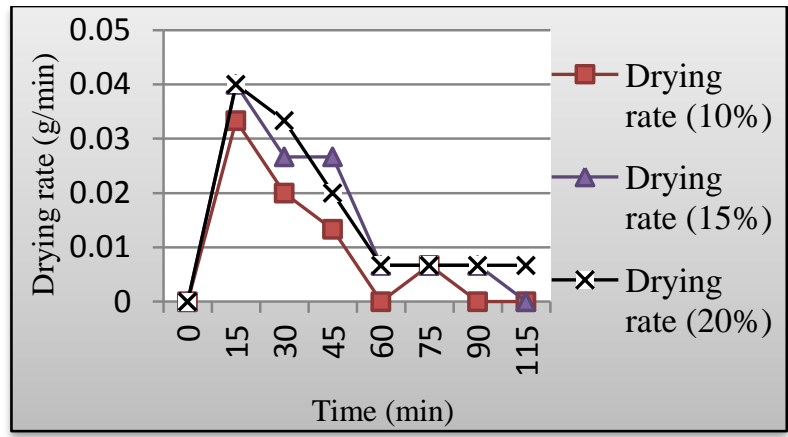

Figure 6. Drying rate: constant solution temperature of $25^{\circ} \mathrm{C}$ and varying concentration

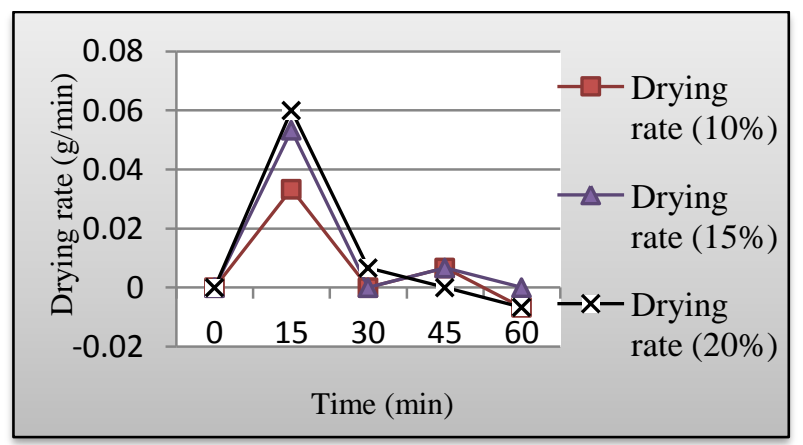

Figure 7. Drying rate: constant solution temperature of $30^{\circ} \mathrm{C}$ and varying concentration

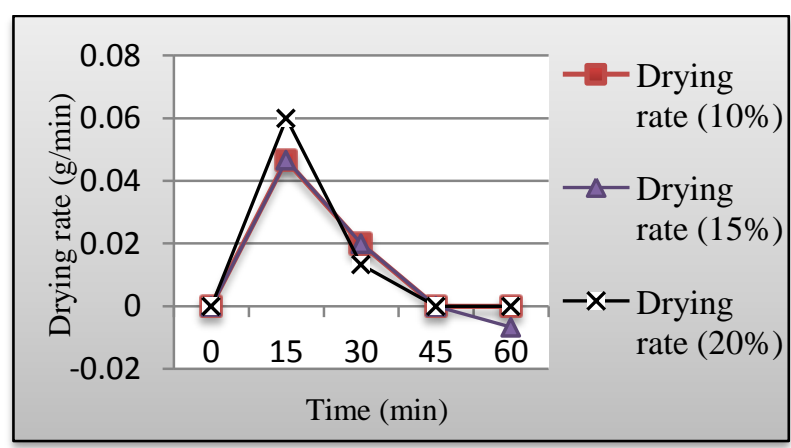

Figure 8. Drying rate: constant solution temperature of $35^{\circ} \mathrm{C}$ and varying concentration

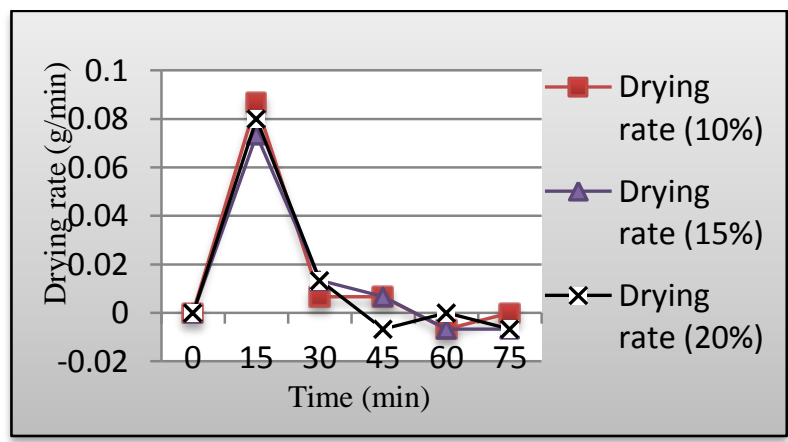

Figure 9. Drying rate: constant solution temperature of $40^{\circ} \mathrm{C}$ and varying concentration 


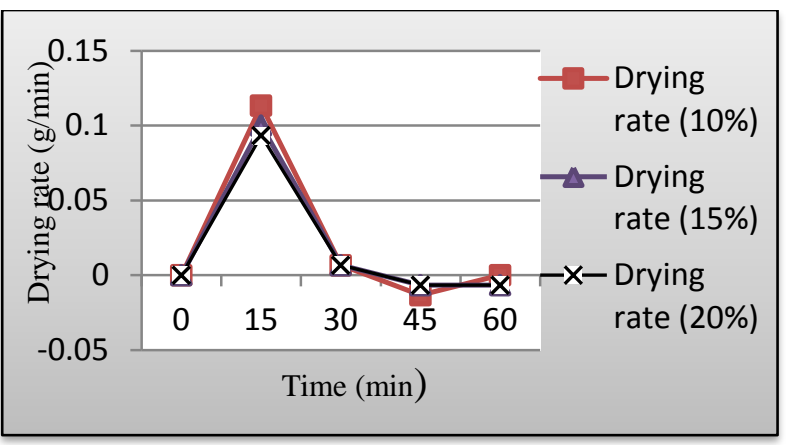

Figure 10. Drying rate: constant solution temperature of $45^{\circ} \mathrm{C}$ and varying concentration

\section{DEVELOPING ARTIFICIAL NEURAL NETWORK (ANN) MODEL USING "elite- $\mathbf{A N N}^{\Theta}$ ":}

The objective of this part of present work is to develop Artificial Neural Network model that will correlate the dependent parameters, the weight loss and drying rate, with temperature, concentration of salt solution and time for osmotic dehydration of beetroot slices using the data generated from experimental runs.

The total data set generated in various experimental runs is divided into two parts. One part is called as training date set whereas the other one as test data set. The training of ANN is done by training data set and its accuracy and effectiveness in estimation is judged by the test data set.
There are three input parameters namely temperature, concentration of salt solution and time duration and two output parameters as weight reduction and osmotic drying rate. The details of topology of ANN models developed using "elite$\mathrm{ANN}^{\Theta}$ " are given in table no. 2. The typical schematic of the sample of ANN architecture used in this part is as shown in figure no 11 .

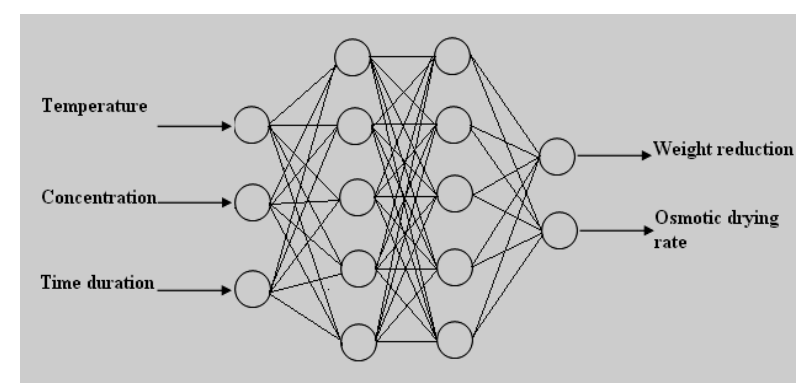

Figure 11. Artificial Neural Network Architecture

Figure no. 12 and 13 shows the graph of comparison of actual and predicted values of weight loss and drying rate for training data set whereas figure no. 14 and 15 show the same for test date set.

As can be seen from these graphs, these values are very close to each other indicating higher accuracy of ANN model developed for correlating these parameters in osmotic dehydration of beetroot slices

Table 2. Details of Topology for ANN model

\begin{tabular}{|c|c|c|c|c|c|c|c|}
\hline \multirow{2}{*}{$\begin{array}{c}\text { Model } \\
\text { code }\end{array}$} & \multicolumn{4}{|c|}{ Number of Neurons } & \multicolumn{3}{c|}{ Date points } \\
\cline { 2 - 9 } & $\begin{array}{c}\text { Input } \\
\text { layer }\end{array}$ & $1^{\text {st }}$ hidden layer & $2^{\text {nd }}$ hidden layer & $3^{\text {Td }}$ hidden layer & Output layer & $\begin{array}{c}\text { Training } \\
\text { data set }\end{array}$ & $\begin{array}{c}\text { Test data } \\
\text { set }\end{array}$ \\
\hline BS & 3 & 0 & 5 & 5 & 2 & 50 & 9 \\
\hline BM & 3 & 0 & 10 & 10 & 2 & 50 & 9 \\
\hline BC & 3 & 10 & 10 & 10 & 2 & 50 & 9 \\
\hline
\end{tabular}

BS: Model for Simple complexity; BM: Model for Moderate complexity; BC: Model for complex complexity; Input: Temperature, concentration and time Output: Weight loss and drying rate.

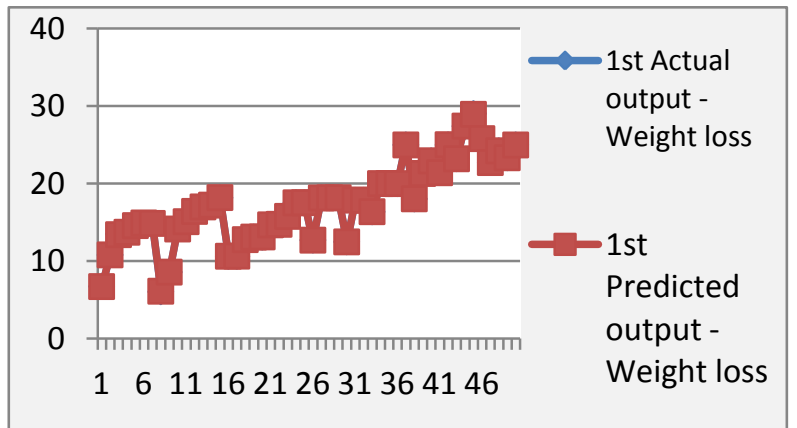

Figure 12. Comparison of actual and predicted values of weight loss for training data set

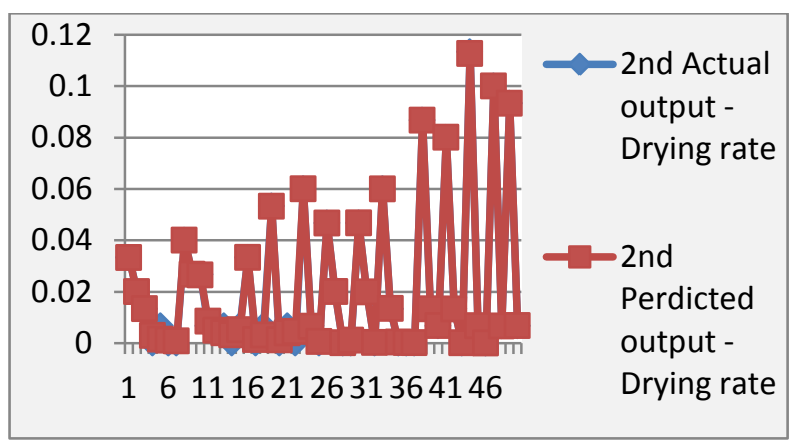

Figure 13. Comparison of actual and predicted values of osmotic drying rate for training data set 


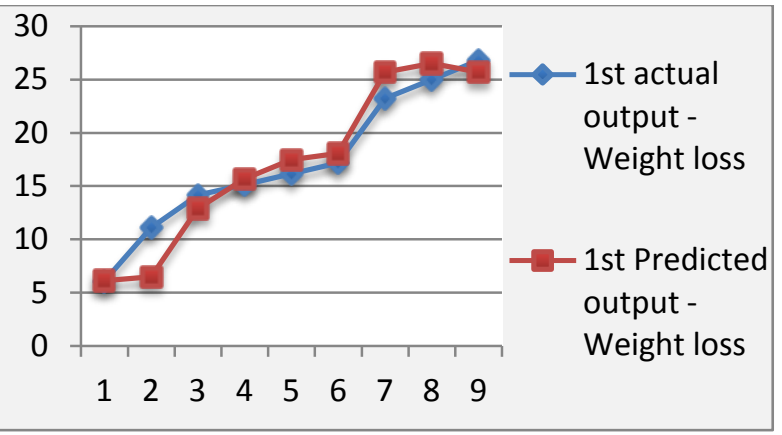

Figure 14. Comparison of actual and predicted values of weight loss for test data set

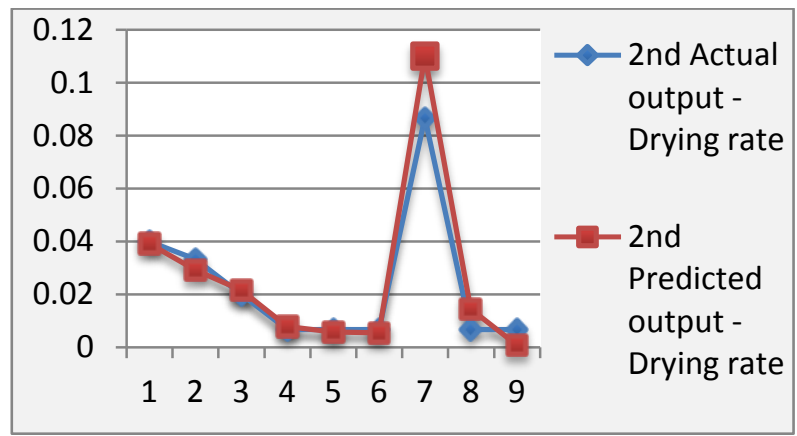

Figure 15. Comparison of actual and predicted values of weight loss for test data set

\section{CONCLUSION}

Based on the observations, results $\&$ discussion, it can be said that, beetroot slices can be partially dewatered by osmotic dehydration in salt solution and percent weight loss is from 10 to $29 \%$ depending upon the operating parameters like salt solution concentration, solution temperature and time for osmosis.

The favored operating parameters were salt solution concentration of $10 \%$, temperature of $45^{\circ} \mathrm{C}$ and time duration of osmosis around 30 minutes for which the maximum weight loss of $29.03 \%$ is obtained.

It can be concluded that the ANN model developed for correlating the parameters was successful with high accuracy level with an average percentage error of 0.255 acceptable.

\section{ACKNOWLEDGMENT}

Authors wish to express their sincere gratitude towards Director, Laxminarayan Institute of Technology, Nagpur for constant encouragement and the facilities provided.

\section{REFERENCES}

[1] Manivannan, P., and Rajasimman, M., International Journal of Chemical and Biological Engineering 1:4 2008.

[2] Kar, A., Chandra, P., Prasad, R., Samuel, D. V. K., Khurdiya, D. S., Journal of Agricultural Engineering, Vol. 38, No. 3, 2001.

[3] Antonio, G. C., Azoubel, P. M., Alves, D. G., and Fernanda E. X. M., Drying 2004 - Proceedings Of The 14th International Drying Symposium (IDS 2004) São Paulo, Brazil, 22-25 August 2004, Vol. C, pp. 1998-2004.

[4] Nikolaos, E. M., Vassilis, G., Ingegerd, S., Journal of Food Engineering, Volume 35, Issue 2, February 1998.

[5] Alam, M. S., Singh, A., International Journal of Food Engineering, Volume 6, Issue 1, February 2010.

[6] Gordana, B. K., Nevena, M. M., Ljubinko, B. L., Lidija, R. J., and Bojana, V. F., APTEFF, 41, 1-203 (2010).

[7] Fernanda, E. X. M., Jose, L. B. J., Denise, G. A., Anoar, A. El-A., and Eder, A. F. A., Drying 2004 - Proceedings of the 14th International Drying Symposium (IDS 2004) Sao Paulo, Brazil, 22-25 August 2004, Vol. C, pp. 1992-1997.

[8] Anderson, J.A., an Introduction to Neural Networks (Prentice-Hall of India, Pvt Ltd New Delhi), 1999.

[9] Rumelhart, D. E., and McClleland, Back Propagation Training Algorithm Processing, M.I.T Press, Cambridge Massachusetts, (1986).

[10] Fan, J. Y., Nikolau, M., and White, R. E., AIChE, 39 (1) (1993) 82.

[11] Hoskins, J. C., Kaliyur, K. M., and Himmelblau, D. M., AIChE, 37(1) (1991) 137.

[12] Watanabe, K., Abe, M., Kubota, M., and Himmelblau, D. M., AIChE, 35 (11) (1989) 1803.

[13] Belsito, S., and Banerjee, S., AIChE 44 (12), (1998), 2675.

[14] Pandharipande, S. L., and Badhe, Y. P., Chem Engg World 38(6) (2003) 70

[15] Pandharipande, S. L., Paul, S., and Singh, A., International Journal of Computer Applications (0975 - 888), Volume 48- No.3, June 2012.

[16] Pandharipande S L \& Badhe Y P, elite-ANN@, ROC No SW-1471/2004. 